eight patients who had a stable or partial response, suggesting that, in addition to causing sclerosis of bone, APD may have an antitumour effect. Factors released from tumours stimulate osteoblastic activity ${ }^{3}$ and osteolysis mediated by osteoclasts. ${ }^{4}$ APD is a potent inhibitor of osteoclast function, and such inhibition combined with the osteoblastic factors produced by tumour cells may explain the bony sclerosis seen in this study.

APD reduces morbidity from lytic metastases when used in conjunction with standard chemotherapy, ${ }^{1}$ and this study shows that it may be active when used alone.

We are grateful to the staff of the day ward, Christie
Hospital; the departments of chemical pathology at Christie Hospital and Withington Hospital; Mrs $\mathrm{H}$ Morten and $\mathrm{Mr}$ $\mathrm{J}$ Turnbull for performing the radioimmunoassays; and Ciba-Geigy Ltd for supplies of APD and for financial support.

1 Van Holten-Verzantvoort ATh, Bijvoet OLM, Hermans J, et al. Reduced morbidity from skeletal metastases in breast cancer patients during long-term bisphosphonate (APD) therapy. Lancet 1987;ii:983-5.

2 Pons-Anicet DMF, Krebs BP, Mira R, Namer M. Value of CA 15:3 in the follow-up of breast cancer patients. Br f Cancer 1987;55:567-9.

Pfeilschifter J, D'Souza SM, Mundy GR. Effects of transforming growth factor- $\beta$ on osteoblastic osteosarcoma cells. Endocrinology 1987:121:212-8.

Ibbotson KJ, Harrod J, Gowen $M$, al Human recombint grow vitro. Proc Natl Acad Sci USA 1986;83:2228-32.

(Accepted 8fuly 1988)

\section{Tolerance of intravenous indomethacin treatment for premature infants with patent ductus arteriosus}

\author{
Margaret Walters
}

Merck Sharp and Dohme Ltd, Hoddesdon, Hertfordshire EN11 9BU Margaret Walters, BSC, adverse experiences monitor
Following the observation that prostaglandin $E_{1}$, dilates the ductus arteriosus in fetal and neonatal animals, indomethacin-a potent inhibitor of prostaglandin synthesis- has been used for some years as an alternative to surgical ligation of the patent ductus arteriosus in premature infants with cardiac failure.

Giving the drug by mouth has been associated with variable absorption and local effects in the gastrointestinal tract. ${ }^{2}$ An intravenous formulation was developed to ensure bioavailability, and this report concerns the adverse event profile in 2482 premature infants who received intravenous indomethacin (Indocid PDA).

\section{Methods and results}

Since 1980, 2482 preterm neonates in the United Kingdom have received intravenous indomethacin (recommended dosage $0.2 \mathrm{mg} / \mathrm{kg}$ intravenously with second and third doses given at 12-24 hour intervals if required) on a named patient or humanitarian basis. All supplies were accompanied by a request to report any adverse events to Merck Sharp and Dohme forthwith (cases not resulting in a report were not followed up). Treatment was contraindicated in infants with proved or suspected infections; evidence of necrotising enterocolitis; gastrointestinal bleeding; intraventricular haemorrhage; coagulation defects; and appreciable impairment of renal function.

Reports of adverse events in 146 neonates $(6 \%)$ were reviewed; of these, 73 (3\% of total) were rated as being possibly, probably, or definitely related to the drug treatment by the reporting physician. The table gives details of the adverse events reported. None of the 61 deaths reported were considered by the reporting physicians to be drug related. In three cases in which infants had other life threatening conditions from birth the effect of indomethacin on renal function might have contributed to the death. The cases of renal impairment observed were not usually sustained or serious, but in cases of pre-existing renal impairment (when indomethacin is contraindicated) treatment may provoke severe deterioration. Increased creatinine concentrations and hyponatraemia were reported, but both these and renal function returned to normal on closure of the patent ductus arteriosus or cessation of drug treatment. The reported instances of gastro- intestinal haemorrhage were generally detected by nasogastric aspiration two to three days after administration of indomethacin, and most resolved within the next few days with no reported complications.

Details of adverse events occurring in 146 out of 2482 infants treated with intravenous indomethacin for patent ductus arteriosus and of those related to drug treatment in 73 infants ${ }^{\star}$

\begin{tabular}{|c|c|c|c|c|c|}
\hline \multirow[b]{2}{*}{ Adverse event } & \multirow{2}{*}{$\begin{array}{l}\text { Total } \\
\text { No of } \\
\text { reports }\end{array}$} & \multirow{2}{*}{$\begin{array}{c}\text { No } \\
\text { related } \\
\text { to drugt }\end{array}$} & \multicolumn{3}{|c|}{ Severity } \\
\hline & & & Mild & Moderate & Severe \\
\hline \multicolumn{6}{|l|}{ Intraventricular } \\
\hline Gastrointestinal bleeding & 19 & $18(0.73)$ & 8 & 5 & 5 \\
\hline Necrotising entercolitis & 24 & $13(0.52)$ & 2 & 4 & 7 \\
\hline Renal failure or shutdown & 15 & $10(0.4)$ & $i$ & 5 & 4 \\
\hline Fall in urea concentration & 12 & $12(0.48)$ & 4 & 6 & 2 \\
\hline Hyponatraemia & 18 & $16(0.65)$ & 2 & 10 & 4 \\
\hline \multicolumn{6}{|l|}{ Increased creatinine } \\
\hline concentration & 6 & $5(0 \cdot 2)$ & 0 & 5 & 0 \\
\hline Decreased platelet function & 2 & $2(0.08)$ & 2 & 0 & 0 \\
\hline Death & 61 & 0 & & & \\
\hline Seizures & 2 & 0 & & & \\
\hline Jaundice & 8 & 0 & & & \\
\hline
\end{tabular}

*Total numbers of events exceed the numbers of infants affected. † As determined by reporting physician. Values in parentheses are percentages of 2482 infants.

\section{Comment}

The rate of successful closure of a patent ductus arteriosus with oral indomethacin has been highly variable $(18-85 \%)^{3}$ but appears to be less variable with intravenous treatment $(79-91 \%){ }^{2}$ The best responses are achieved when neonates are treated in the first two weeks of life.

A review of indomethacin in the treatment of patent ductus arteriosus lists as the most important adverse effects transient impairment of renal function and decreased platelet function with possible clinical bleeding, including gastrointestinal and intraventricular haemorrhage ${ }^{4}$ Our findings in a large series of patients identified changes in renal function with associated electrolyte imbalance and gastrointestinal bleeding as the most common drug related effects. Necrotising enterocolitis and intraventricular haemorrhage were also prominent, although the haemorrhage was not often considered by the physician to be related to treatment. The relation between drug administration and necrotising enterocolitis and intraventricular haemorrhage is difficult to assess as preterm infants with patent ductus arteriosus are predisposed to these conditions, and studies have failed to detect an enhanced risk with indomethacin treatment. ${ }^{5}$

In conclusion, these data on 2482 preterm infants treated with intravenous indomethacin indicate that the incidence of adverse events is low. The commonest unwanted effects were transient impairment of renal function and gastrointestinal bleeding, which resolved on withdrawal of the drug. The efficacy of intravenous indomethacin in patent ductus arteriosus is well docu- 
mented, ${ }^{3}$ reflecting the reliable bioavailability with this route. Although direct comparison with oral indomethacin has not been undertaken, intravenous indomethacin appears to be at least as well tolerated and should be preferred for the treatment of patent ductus arteriosus.

1 Clyman RI, Heymann MA. Pharmacology of the ductus arteriosus. Pediatr Clin North Am 1981;28:77-93.
2 Vert P, Bianchetti G, Marchal F, Monin P, Morselli PL. Effectiveness and pharmacokinetics of indomethacin in premature newborns with patent ductus arteriosus. Eur 7 Clin Pharmacol 1980;18:83-8.

3 Merritt TA, Bejar R, Corazza M, Ikonen RS, Davis R, Rosenberg M. Clinical trials of intravenous indomethacin for closure of the patent ductus arteriosus. Pediatr Cardiol 1983;4:71-9.

4 Del Favero A. Side effects of drugs annual 10. Amsterdam: Elsevier, 1986:80-1. 5 Corazza MS, Davis RF, Merritt TA, Bejar R, Cvetnic W. Prolonged bleeding time in preterm infants receiving indomethacin for patent ductus arteriosus. I Pediatr 1984;105:292-6.

(Accepted 24 May 1988)

\section{Maternal age, illegitimacy, and postneonatal mortality}

\section{R R Gordon, R Sunderland}

Gosfield Hall, Near Halstead, Essex CO9 1SF R R Gordon, FRCP, retired consultant paediatrician

Selly Oak Hospital, Birmingham B296JD

$\mathrm{R}$ Sunderland, $\mathrm{MD}$, consultant paediatrician

Correspondence to: $\mathrm{Dr}$ Gordon.
Postneonatal mortality is widely used as an indicator of infant health, although positive proof of a correlation is lacking; this variable has the advantage of being consistently recorded nationally. In the first 75 years of this century, when the major registered causes of postneonatal death were infections, postneonatal mortality was regarded as an indicator of associated social conditions. Nowadays the main causes of postneonatal death are the sudden infant death syndrome $(43 \cdot 8 \%)$ and congenital anomalies (18.5\%); infections of all
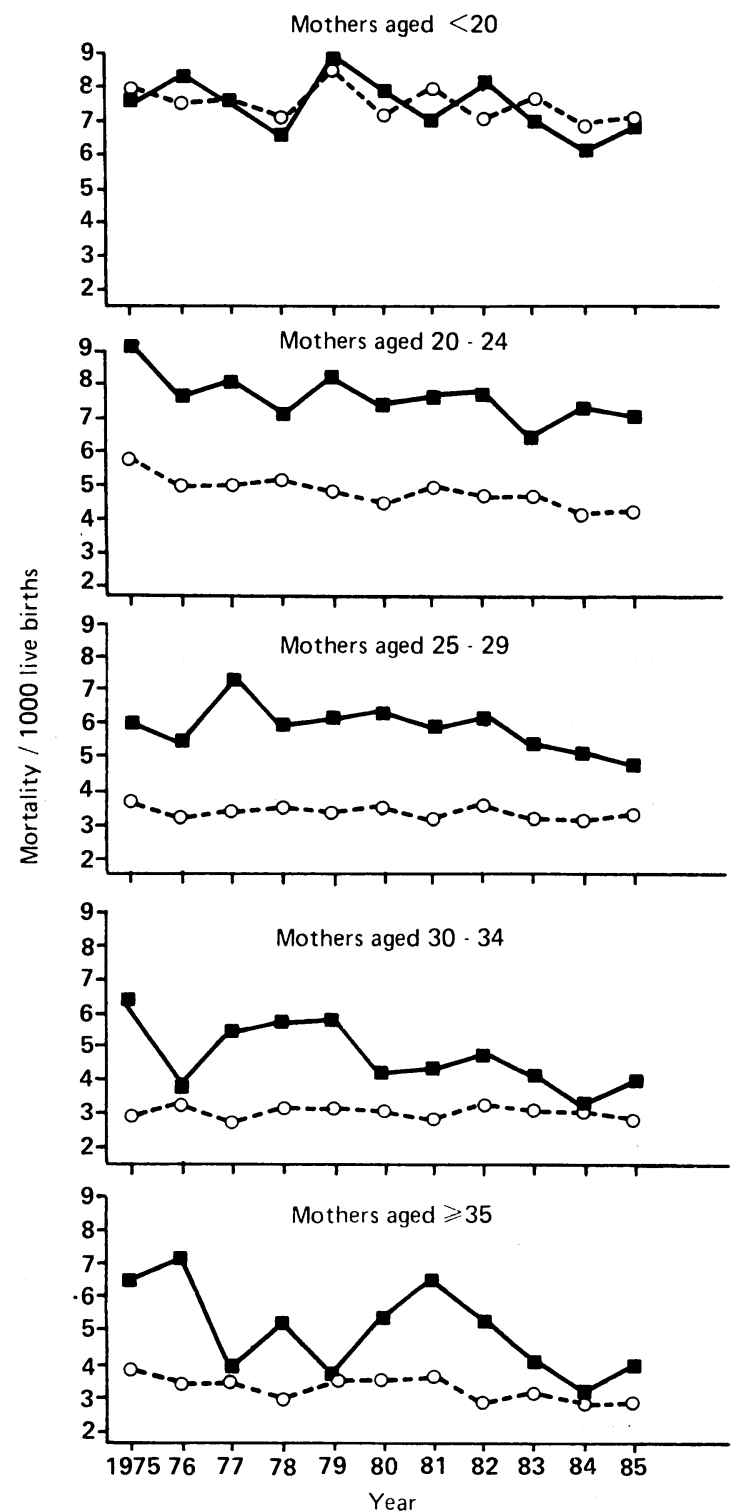

kinds now account for only $16.4 \%$, and there is debate over whether some deaths registered as due to respiratory infections may in fact have been due to the sudden infant death syndrome..$^{1-4}$ Congenital anomalies alone show no social gradient. While seeking aetiological mechanisms for differences in postneonatal mortality we examined their relation to maternal age and illegitimacy.

\section{Methods and results}

All data were derived from tables compiled by the Office of Population Censuses and Surveys listing postneonatal mortality during $1975-85$. The numbers of legitimate and illegitimate live births were obtained from Fertility Trends (series FM1) and details on postneonatal mortality from the $\mathrm{DH} 3$ series. The figure shows that for all maternal ages beyond 20 the postneonatal mortality among illegitimate babies was consistently higher than that among legitimate babies. For teenage mothers, however, the rates were the same but at the high level seen among illegitimate babies.

\section{Comment}

Since Victorian times illegitimate babies have been known to have a reduced chance of survival. Traditional arguments relating to poverty and lack of access to medical care became less relevant with the advent of the welfare state, yet the difference persists. The exact cause is unclear but must lie within the plethora of circumstances classed as social. The rising illegitimacy rate may have contributed to the recent rise in postneonatal mortality in the United Kingdom. Since 1975 there has been a consistent increase (from $9 \%$ to $19 \%$ ) in the proportion of illegitimate live births in England and Wales. Sixty five per cent of all babies born to mothers aged under 20 are now illegitimate. Many of these mothers live in inner cities, and this trend, which does not seem to be related to failure of contraception, may have serious implications for the NHS.

This study found that legitimate babies born to young mothers are also at increased risk of postneonatal death. This finding conflicts with data from a Swedish study of the sudden infant death syndrome, ${ }^{5}$ but the number of married mothers under 20 in that study was small and the incidence of the syndrome in Sweden subsequently rose. The increased risk of postneonatal death among babies of young mothers (married or not) may be due to lack of maternal skills or support; perhaps the educational priorities for teenagers should be reappraised.

\footnotetext{
Keeling JW, Golding J, Sutton B. Identification of cases of sudden infant death syndrome from death certificates. If Epidemiol Community Health 1985;39:148-51.

2 Madeley RJ, Hull D, Holland T. Prevention of postneonatal mortality. Arch Dis Child 1986;61:459-63.

Gordon RR. Whatever happened to the Black report? Br Med f 1986:293:758-9. 4 Sunderland R, Sunderland EP. Invalid certification of young deaths. Arch Dis Child 1983,58:867-74.

5 Norvenius SG. Sudden infant death syndrome in Sweden in 1973-77 and 1979. Acta Paediatr Scand [Suppl] 1987;333:1-138.

(Accepted 24 May 1988)
} 